\title{
Mobile Learning for Undergraduate Course through Interactive Apps and a Novel Mobile Remote Shake Table Laboratory
}

\section{Alec Maxwell, San Francisco State University}

Alec Maxwell is currently an undergraduate student in the School of Engineering at San Francisco State University (SFSU). Besides actively conducting research on innovative tools for engineering education in the Intelligent Structural Hazards Mitigation Laboratory at SFSU with Prof. Zhaoshuo Jiang, he also is interested in acquiring his Masters degree in structural engineering.

\section{Dr. Zhaoshuo Jiang P.E., San Francisco State University}

Prof. Jiang graduated from the University of Connecticut with a Ph.D. degree in Civil Engineering. Before joining San Francisco State University as an assistant professor, he worked for Skidmore, Owings \& Merrill (SOM) LLP. As a licensed professional engineer in the states of Connecticut and California, Dr. Jiang has been involved in the design of a variety of low-rise and high-rise projects. His current research interests mainly focus on Smart Structures Technology, Structural Control and Health Monitoring and Innovative Engineering Education.

\section{Dr. Cheng Chen, San Francisco State University}

Dr. Cheng Chen is currently an associate professor in the school of engineering at San Francisco State University. His research interests include earthquake engineering, structural reliability and fire structural engineering. 


\title{
Mobile Learning for Undergraduate Course through Interactive Apps and a Novel Mobile Remote Shake Table Laboratory
}

\author{
Alec Maxwell ${ }^{1}$, Zhaoshuo Jiang ${ }^{2 *}$, and Cheng Chen $^{3}$ \\ ${ }^{1}$ Undergraudate Student, School of Engineering, San Francisco State University \\ ${ }^{2}$ Assistant Professor, School of Engineering, San Francisco State University \\ ${ }^{3}$ Associate Professor, School of Engineering, San Francisco State University \\ *Corresponding Author: zsjiang@sfsu.edu
}

\begin{abstract}
Learning style changes from generation to generation. With the advancement of technologies, the current and incoming tech-savvy learners grow up with the digital world. Such technology advancement makes learning more accessible. As one of the examples, mobile learning has become a commonly accepted and embraced concept among the younger generations. Effective learning occurs when the teaching styles align well with the learning styles. To better serve the need of the next-generation learners in a more accessible way, a standalone mobile learning module was developed for an undergraduate upper division class, Mechanical and Structural Vibration, at San Francisco State University (SFSU). The developed mobile learning module consisted of three interconnected components, namely Analysis, Simulation and Experiment, representing the three important elements in a good engineering learning environment - theory, practical example and physical experimentation. Besides delivering the theoretical knowledge and important concepts, the learning module also allows students further examine the gained knowledge through animated simulations in the interactive Apps. In addition, the module includes a mobile remote shake table laboratory (RSTLab) which provides students the opportunity to remotely participate and conduct physical shake table experiments in real-time through smart mobile devices (e.g. smartphones and tablets). Through these physical experiments, students may easily use scaled physical models to test theories and implement their own innovations to observe how structures behave under different ground excitations. A telepresence robot is innovatively adopted and integrated with the mobile RSTLab to actively engage students and provide them a real sense of in-person participation without the need of being physically present in the laboratory.
\end{abstract}

The learning module was implemented in Fall 2016 at SFSU as a "flipped laboratory". Pre- and post- surveys were conducted to evaluate the effectiveness of the mobile learning module to fulfil course learning outcomes. Survey results demonstrated the readiness of the mobile learning and improvement in participants' knowledge competence after using the module. The obtained information will be utilized to guide the future refinement of the learning module and understand what strategies could be used to better fit the need of the new generation learners.

\section{Introduction}

Student learning style evolves with time. Gioia and Brass ${ }^{1}$ in 1985 noted that the college students being taught then were a "TV Generation", who were raised in an environment dominated by visual images. In early 2000, the new "Virtual Generation" appeared with prevalent virtual 
media such as Internet and videogames ${ }^{2}$. While it may not be necessarily a single or even dominant learning style for any generation of students, it is necessary to understand what is the need for the current and upcoming generations. The current and incoming tech-savvy learners grow up with the digital world. The advancement of technologies makes learning more accessible. Mobile learning has become a commonly accepted and embraced concept among the younger generations ${ }^{3}$. Keegan anticipated that mobile learning would become a harbinger of the future of learning ${ }^{4}$. With the mobile devices that have become part of our daily life, how to use them to help and engage learners is a question that deserves further consideration.

Engineering is a practical science. Hands-on experiments have been proven to be an effective means to consolidate theory and provide insight to challenges in practical applications. Benchscale shake table (earthquake simulator) is an engaging tool to conduct hands-on experiments on physical structures with modern instrumentation (e.g. sensors and data acquisition system) which educates students about the importance of earthquake engineering and how structures respond to different ground motions. Through these hands-on experiments, students may easily use scaled models to test the theories and implement their own innovations to examine how structures behave. However, the opportunity to conduct such experiments may not always be available to students due to many restrictive factors such as the lack of equipment, room capacity, testing schedule, accessibility of the facility, and safety considerations. In attempts to resolve this problem, some educators and researchers developed virtual laboratories ${ }^{5,6,7}$, in which simulated experiments were realized through computer software to mimic the experience in the laboratory. Although virtual laboratory provides meaningful experience to help consolidate the knowledge, it is difficult to capture all the scenarios and fully replicate the actual physical experiments. To fully represent the real experimental settings, remote laboratories that allow for conducting physical experiments remotely through computers were developed ${ }^{8,9}$. While the remote laboratory offers the ability to participate physical experiments remotely, users need computers to access experiments. In addition, as inherent with virtual laboratory, it may create a passive environment where the views and observations are confined within certain setups ${ }^{10}$.

Advancement of technologies and the emergence of the Internet of Things (IoT) make it possible to further strengthen the accessibility of the remote laboratory. An innovative mobile Remote Shake Table Laboratory (RSTLab) was recently developed in San Francisco State University (SFSU) which provides students the opportunity to remotely participate and conduct physical shake table experiments in real-time through smart mobile devices (e.g. smartphones and tablets). To alleviate the passive participating feeling, a telepresence robot is adopted and integrated with the mobile RSTLab to actively engage students and provide them a real sense of in-person participation without the need of being physically present in the laboratory. The schematic of the mobile RSTLab is shown in Figure 1. An experiment will be initiated by reserving a time slot from a booking system. Once the reservation is made, the student will receive a unique access code through email. This access code will activate a control panel, allowing students to send desired control commands. The commands sent from the student's mobile device will be received by the Control PC that interprets the commands and activates the shake table. In the meantime, the measured data from sensors attached on the specimen will be streamed back to the mobile devices in real-time. Detailed explanations on the different components can be found in reference ${ }^{11}$. 


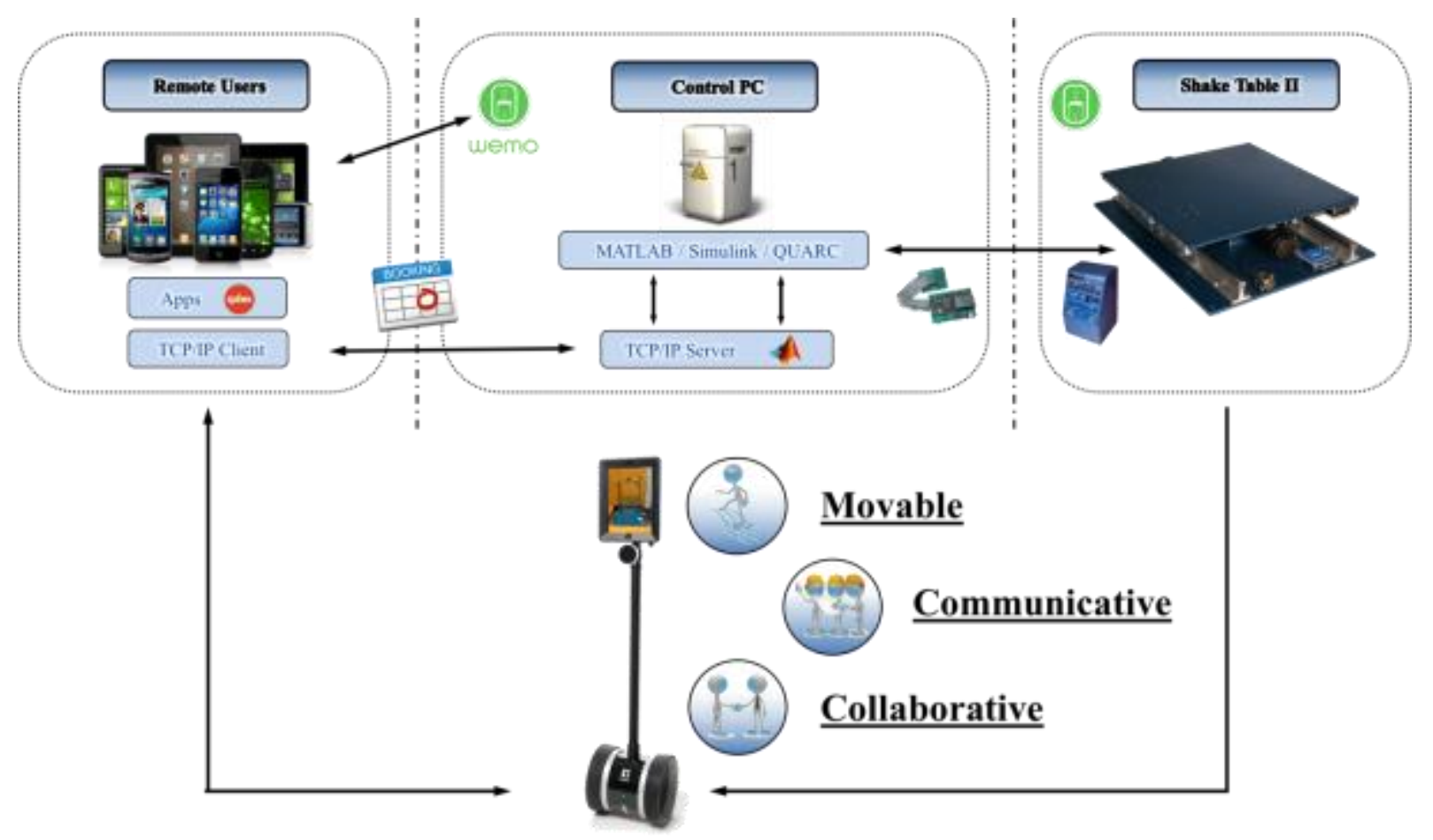

Figure 1. Schematic of the Mobile RSTLab

\section{Implementation}

ENGR 461 - Mechanical and Structural Vibration in SFSU teaches fundamentals in dynamics and vibrations as can be seen by the fact that it is a prerequisite course for five other upper division courses (ENGR 828 - Base Isolation and Energy Dissipation, ENGR 829 - Advanced Topics in Structural Engineering, ENGR 832 - Advanced Topics in Seismic Design, ENGR 833 Principles of Earthquake Engineering, and ENGR 837 - Geotechnical Earthquake Engineering). The course historically has a low success rate (repeatable grades, i.e. D, F, W, in Fall 2015 was $21.2 \%$ ) which greatly jeopardizes students' ability to take the subsequent courses and prevents them from graduating on time. From the past experience, several learning problems contributing to the low success rate include insufficient mastery of key concepts/knowledge, inability to relate the theories taught in class to real-life problems and lack of independent thinking on how to apply the concepts/knowledge. A laboratory section would be very helpful for students to consolidate the fundamental concepts, to relate the knowledge to practical examples, and explore new ideas through experimentation, but currently the course doesn't have any lab component. The developed mobile RSTLab will be an ideal solution to add to the course.

\section{Mobile Laboratory Learning Module}

A good environment for engineering learning is created when a course incorporates theory, practical examples, and physical experimentation ${ }^{10,12}$. Lack of theory severely limits the ability to practicing engineers by the inability to organize facts and use them in new circumstances. On the other hand, without practical applications, theory has little meaning and value to practicing 
engineers. To provide such learning environment with superior accessibility, a standalone laboratory module is developed through interactive mobile apps which will serve as a "flipped laboratory" (analogous to flipped classroom concept) to remove the barriers for student success without the need of sacrificing valuable class time. The developed mobile learning module consists of three interconnected components, namely Analysis, Simulation and Experiment, representing theory, practical example and physical experimentation. The overall goals of combining these components are to help students understand the key concepts, equip them with needed skills and practical hands-on experiences, and educate them on how to apply the gained knowledge and experiences to solve complex and dynamic challenges. The mobile laboratory module goes along with the current generation's learning style and attempts to increase the students' persistence by engaging them and stimulating their active learning. Results obtained from various components will be verified at different stages of the learning process. The learning module as well as the mobile RSTLab are developed through a mobile development platform called qdex ${ }^{\mathrm{TM}}$. The qdex platform is provided by a world leading educational equipment provider, Quanser Inc ${ }^{13}$. It offers the fastest and easiest way to transform conventional static training materials into highly interactive, concept-rich knowledge Apps that fully exploit the convenience and power of mobile devices. The Apps developed via this platform are directly usable in both Android and iOS devices without modifications. The various components of the learning module are connected through a main App called Vibration. After launching the Vibration App, students can navigate to the different components by tapping the corresponding component as seen in Figure 2.
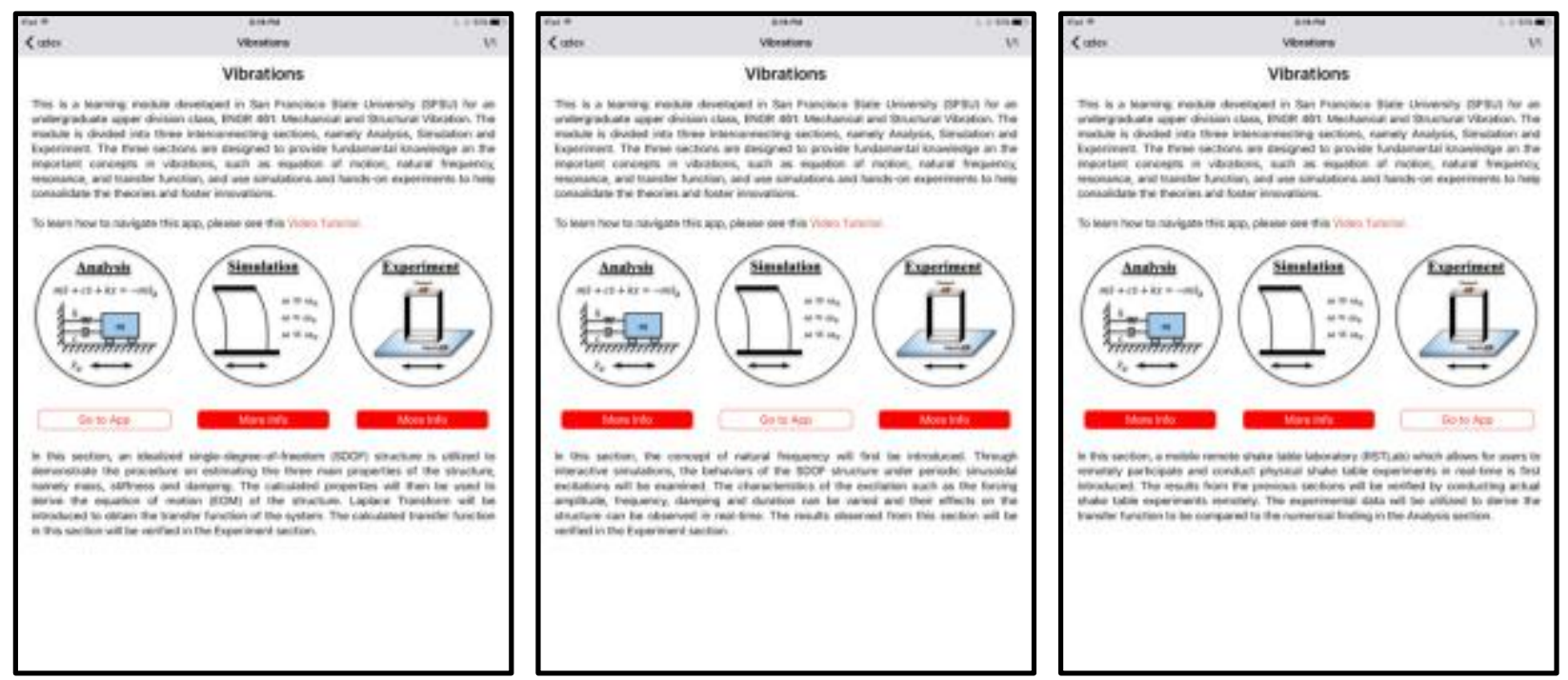

Figure 2. Vibration - Main App

To help achieve the course objectives listed below, the learning module is designed as shown in Figure 3. In the following paragraphs, each component of the module will be introduced.

Obj 1. Enhance understanding of basic system characteristics of a single-degree-of-freedom (SDOF) system.

Obj 2. Develop knowledge of basic responses of the SDOF system to various vibration sources.

Obj 3. Develop understanding for modal responses of multi-degree-of-freedom (MDOF) systems. 
Obj 4. Establish the design concepts for vibration isolation and absorption.

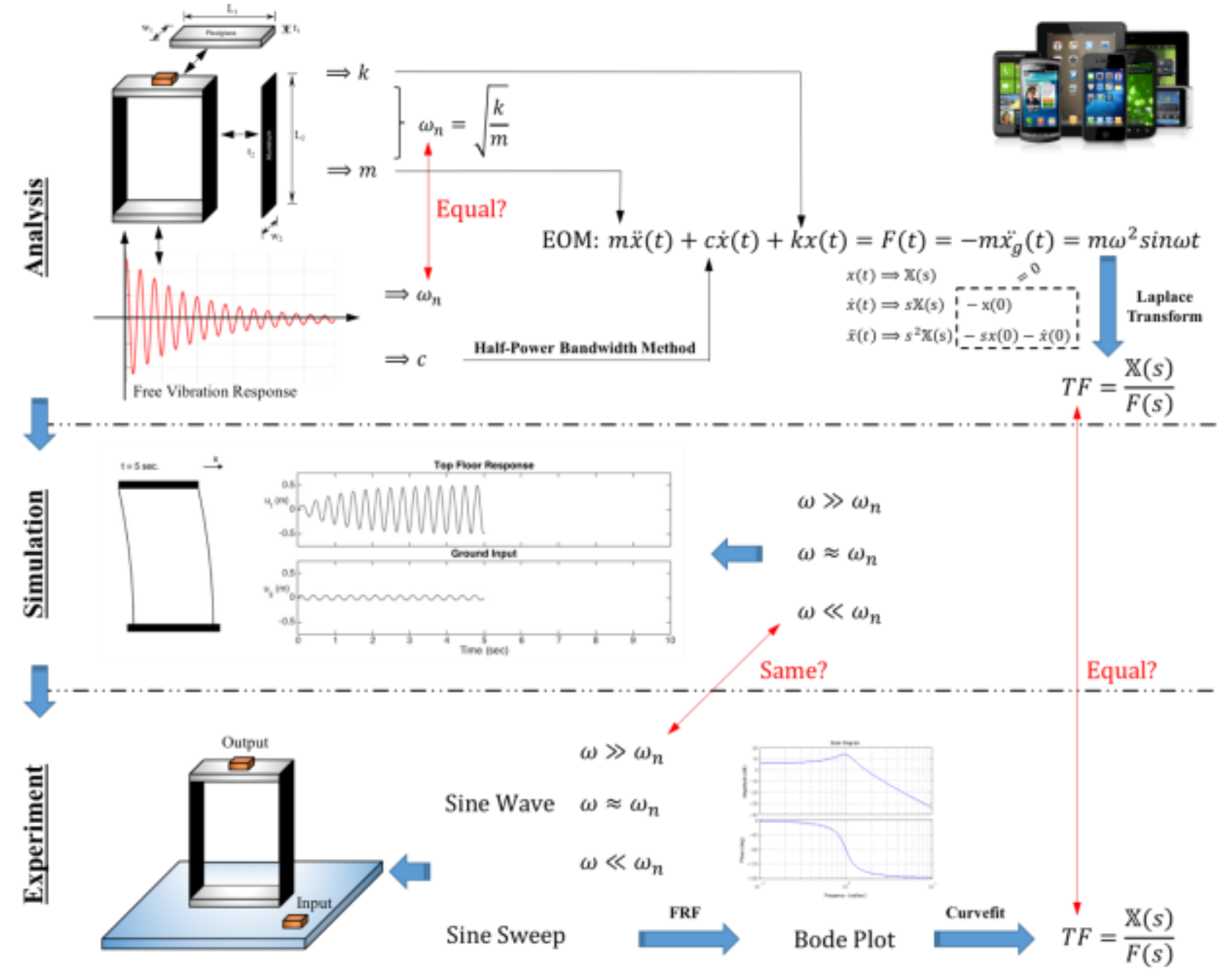

Figure 3. Mobile Learning Module for ENGR 461 - Mechanical and Structural Vibration

\section{Analysis Component}

The Analysis component is designed to provide students necessary theory on how to determine the characteristics of different components of a SDOF system (e.g. mass, stiffness, and damping). Students will be prompted to a SDOF structure after the introduction of the module. As shown in Figure 4a, the dimensions and material properties of the various structural components will be displayed when tapping on each component of the structure. The students are expected to determine the natural frequency of the structure after calculating the mass and stiffness of the structure using the provided dimensions and material information. Animated experimental data from the structure's free vibration response (Figure 4b) is provided to calculate the damping of the system through the use of the half-power bandwidth method. By using the same data, the natural frequency can be found experimentally through inverting the structure period calculated by counting the time needed for the structure to finish one vibration cycle. With the obtained mass, stiffness and damping, students will be taught to derive the transfer function of the system using Laplace Transform. Video Tutorials and Help (highlighted in red on Figure 4a and Figure 4b) are provided throughout the module to assist students as 
needed. Figure 4c shows the hints when the "Help" link under "Damping Ratio $(\xi)$ " in Figure 4b is tapped.

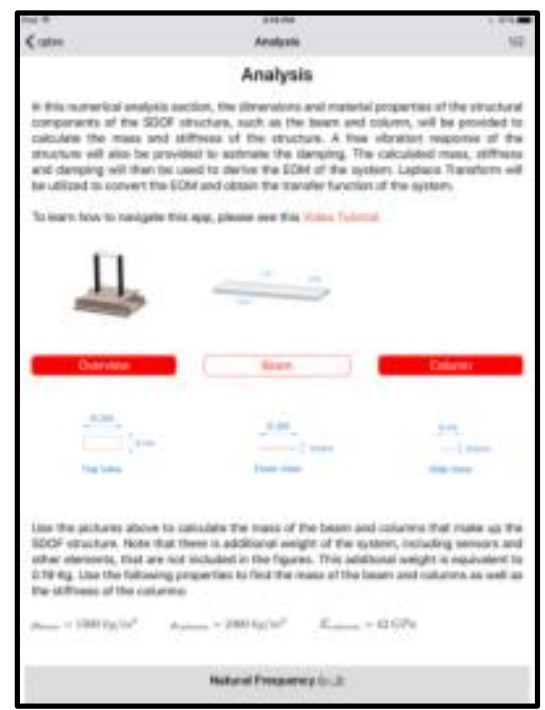

(a)

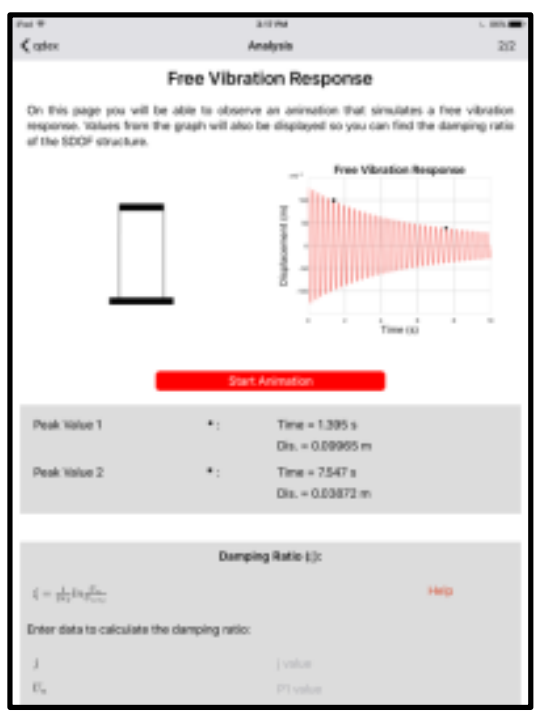

(b)

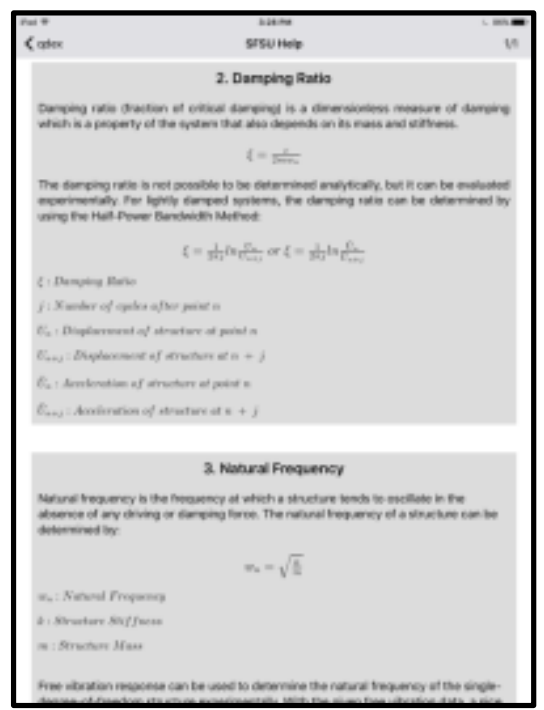

(c)

Figure 4. Vibration - Analysis Component

The objectives of the Analysis component are as following, which are targeted to fulfil course objectives 1 and 4:

- To identify and compute the characteristics of the structural components on a SDOF structure.

- To analyze and determine the system equation of motion and transfer function of a SDOF structure numerically.

\section{Simulation Component}

After learning the necessary theory, students are given the opportunity to verify the gained knowledge by using an interactive SDOF structure model in the Simulation component. Students will be able to excite the structure using a sinewave with different excitation frequencies as shown in Figure 5a. Through this exercise, students can observe the behaviours of the structure when the excitation frequency is smaller than, equal to and larger than the natural frequency, as well as the effect of resonance. To help students test the knowledge, quiz questions are embedded in the Simulation component. Hints will be provided when the answer is incorrect to guide students toward the correct solution (Figure 5b). Note that students can only move on to the next question when the current question is answered correctly. When all the questions are answered correctly, the slider to adjust the damping ratio is unlocked as a bonus for students to test its effect on the behaviour of the structure (Figure 5c). The observed behaviours from the simulated model will be verified in the Experiment component by conducting physical shake table experiments through the mobile RSTLab. 


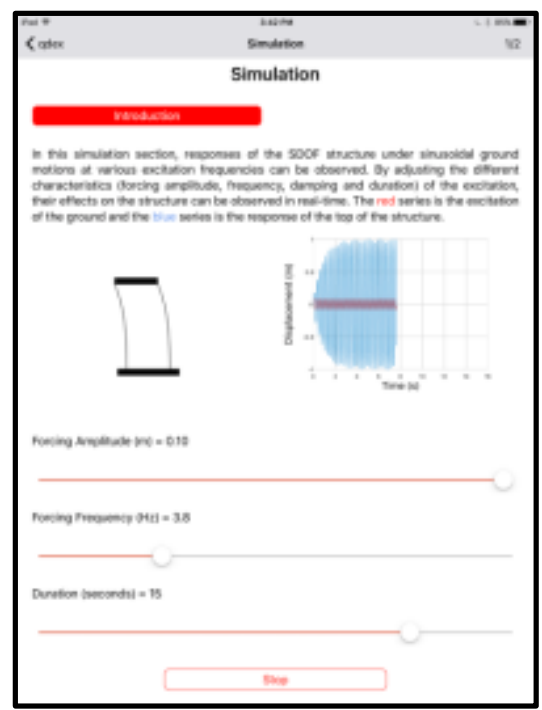

(a)

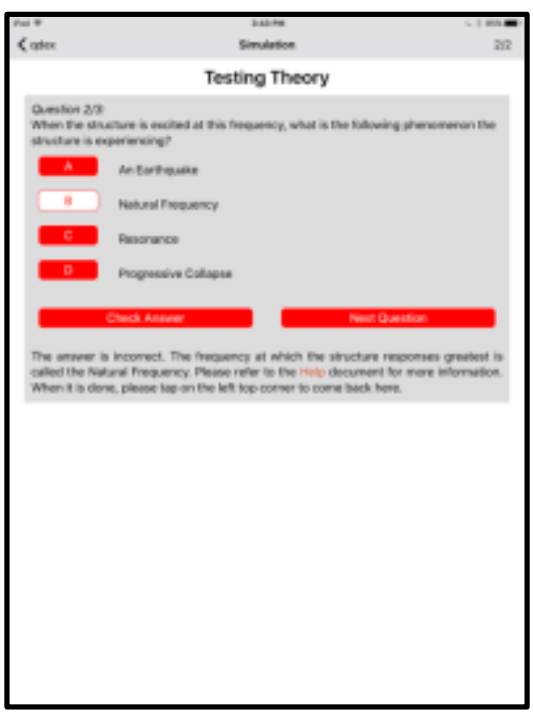

(b)

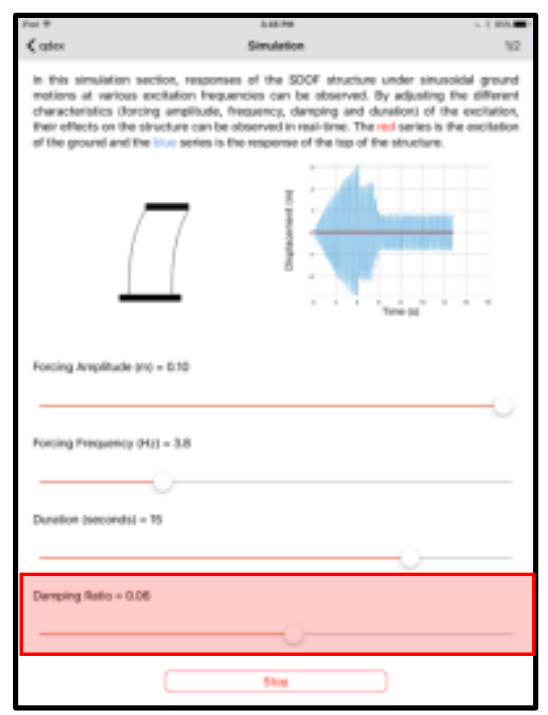

(c)

Figure 5. Vibration - Simulation Component

The objectives of the Simulation component are as following, which are targeted to fulfil course objectives 2 and 4 :

- To observe the behavior of a SDOF structure under excitations with different dominant frequencies numerically

- To understand the concept of natural frequency and its effects on the response of a SDOF structure numerically

\section{Experiment Component}

A numerical model is a valuable tool for students to observe the responses of the SDOF structure, but it may not be able to fully represent its behaviours in the real-world due to factors such as modeling error, assumptions being made, and uncertainties in testing. In the Experiment component, students will be given the opportunity to test a real SDOF structure on a shake table. They can move the shake table at desired frequencies and verify structural responses observed from the Simulation component. Besides the sinusoidal excitations, the students will be asked to send in a sine sweep (sine waves with continuously varying frequencies) signal to excite the structure. The sensor measurements from the mass of the structure and the top stage of the shake table will be streamed back to the mobile device. Students can choose to send the measured data to a specified email address for post-processing or perform the analysis directly on the mobile device. With the data, students can follow the instructions to perform frequency response analyses on the input (sensor measurement from the top stage) and output (sensor measurement from the mass of the structure) of the system to obtain experimentally the structure's natural frequency and its transfer function by curve fitting the data. The natural frequency and transfer function from the experimental testing will then be compared to those obtained numerically from the Analysis component. Explanations are expected, in the final report, on the differences that might be observed between the results from the numerical analysis and the experimental testing. 
When students first launch the app, an animated high-rise building which shakes with the movement of the mobile device is presented to attract their immediate attention (Figure 6a). The building uses the measurements from the accelerometers embedded in the mobile device to drive the animation. After reading through the introduction of the mobile RSTLab, students can reserve a 30-min time slot to conduct an experiment directly on their mobile devices (Figure 6b). Students will gain access to the control panel with the unique access code that is automatically sent to them through email. A timer is displayed on the top left corner as a reminder for the time left to conduct the experiment. Once it counts to zero, the control panel will disappear and the control will no longer be available. The real-time status of the shake table is also shown above the control panel to inform the different stages (e.g. Ready, Command Received, and Calibrating) of the equipment. In addition to the sinewave and sinesweep, students can explore the responses of the structure under different historical earthquake records such as Kobe, El Centro, Northridge and Mendecino (Figure 6c).

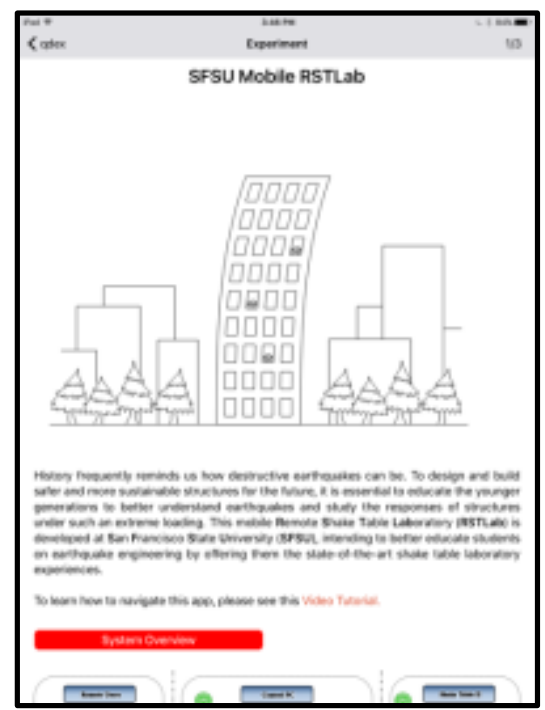

(a)

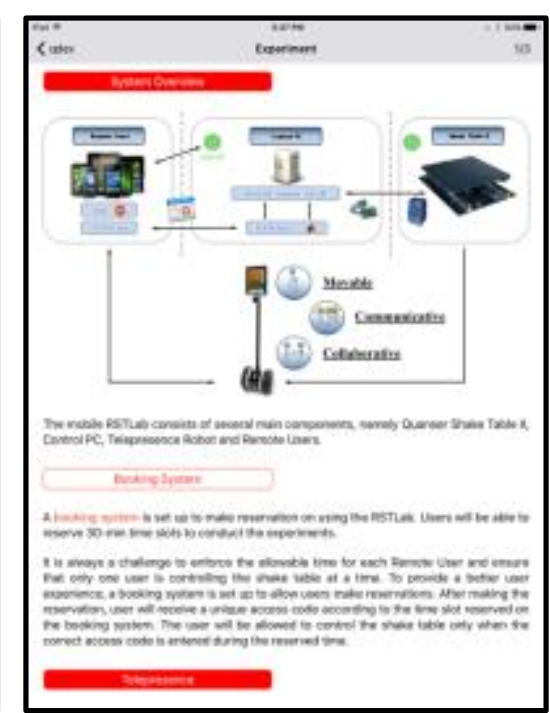

(b)

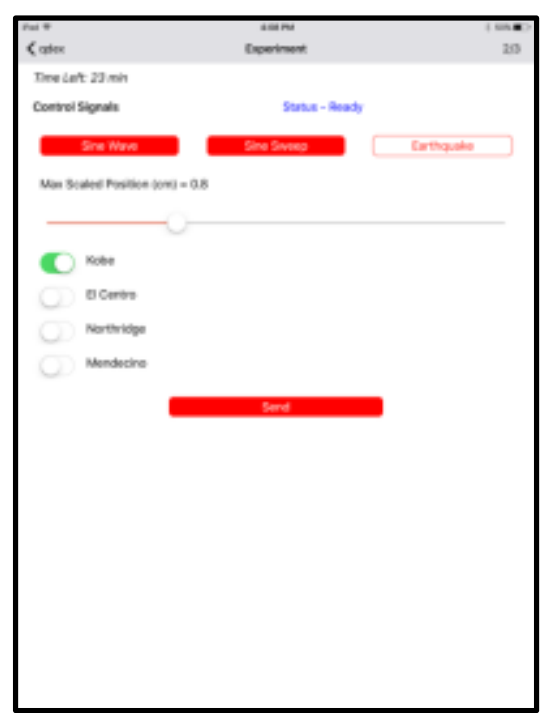

(c)

Figure 6. Vibration App - Experiment Component

As described in previous sections, a telepresence robot is adopted to work with the mobile RSTLab to provide instant visual feedback on the experiment. The telepresence robot, Double, is built by a technology startup company, Double Robotics ${ }^{14}$. It is a remote-controlled robot stand that works together with an Apple iPad to provide low-cost real-time control and communication. A screenshot of the Experiment App exciting the structure with the telepresence robot App running side by side is shown in Figure 7. In this particular experiment, the SDOF structure on the right side of the stand is being excited with a sine wave at its natural frequency. The plot on the Experiment App shows the real-time data measured from the structure (red line is the acceleration measured from the shake table and blue line is the acceleration response measured on the top of the structural mass). Resonance of the structure is observed. 


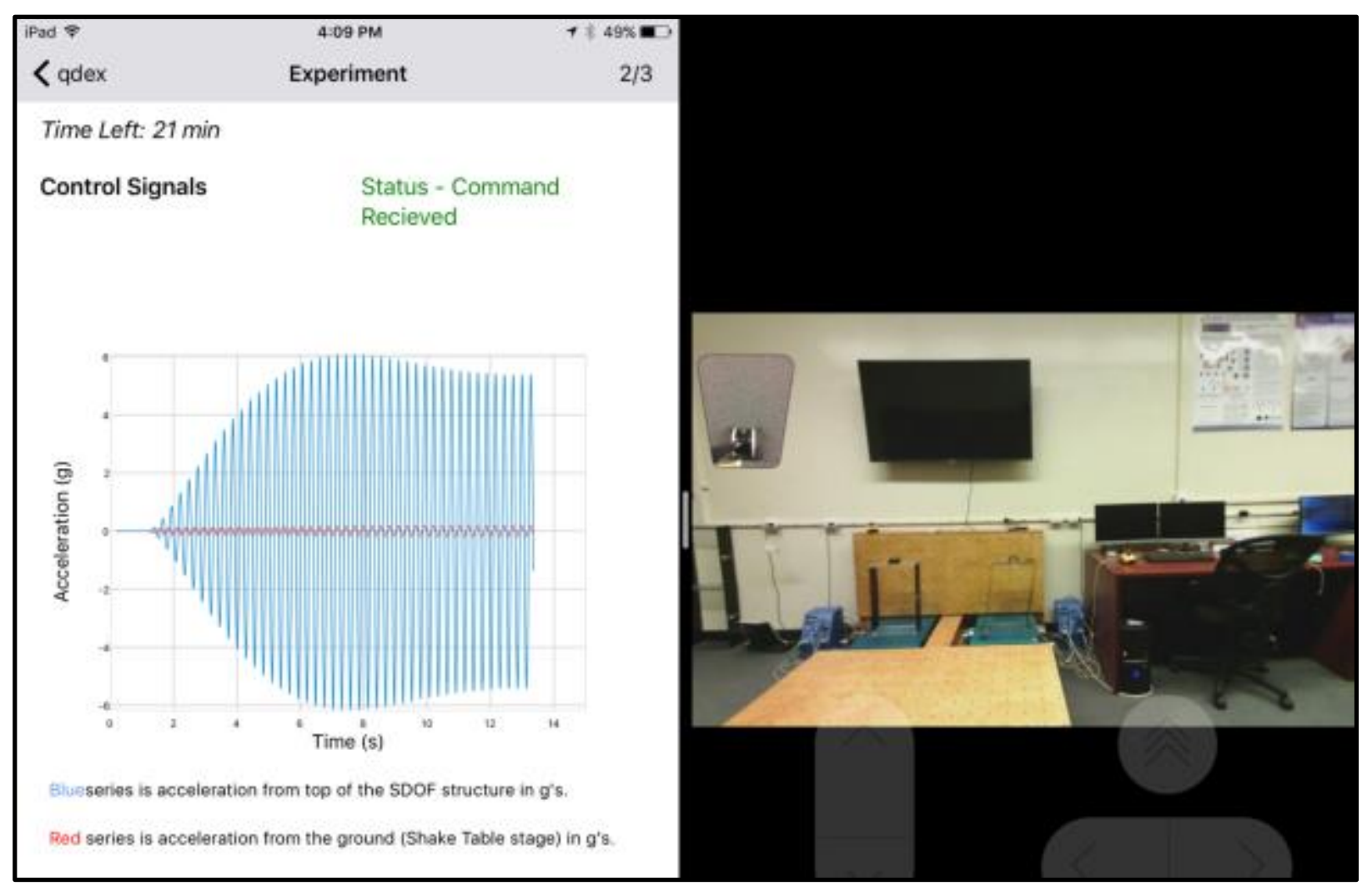

Figure 7. Experiment Component - Real-time Control with Telepresence Robot

After the experiment is conducted, the Experiment App has the ability to replot the data, send it to a specified email address, and perform Fast Fourier Transform (FFT) analysis on the data to obtain the frequency response. Screenshots of the replotted data, sending data through email, and the FFT results are shown in Figure $8 \mathrm{a}, 8 \mathrm{~b}$ and $8 \mathrm{c}$, respectively.

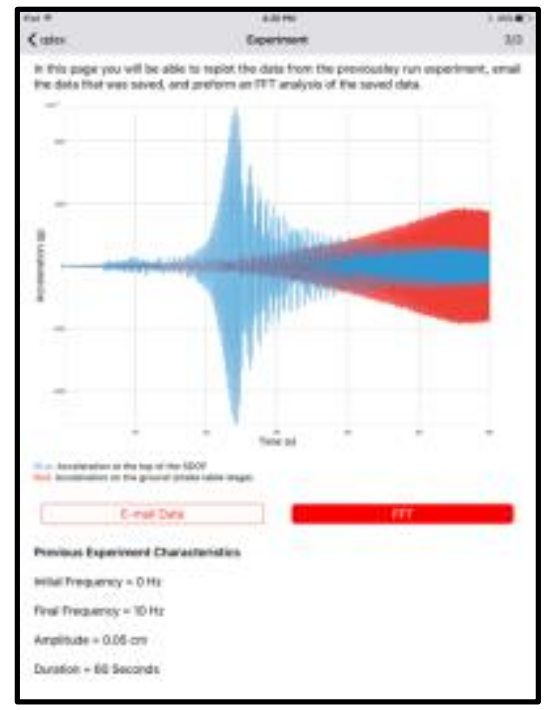

(a)

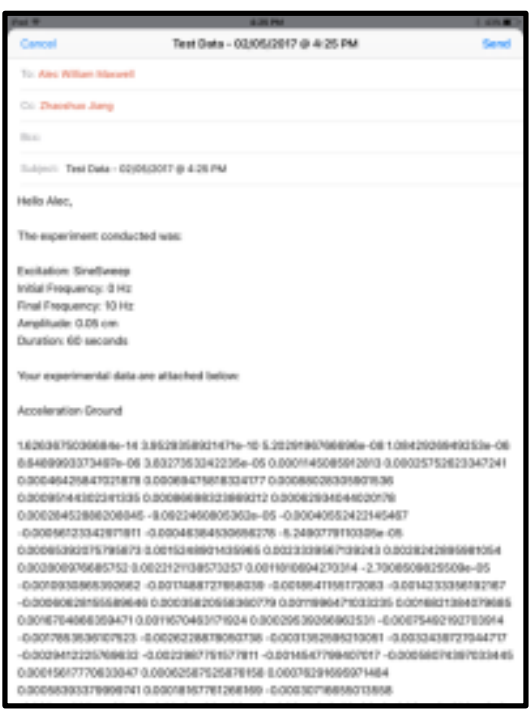

(b)

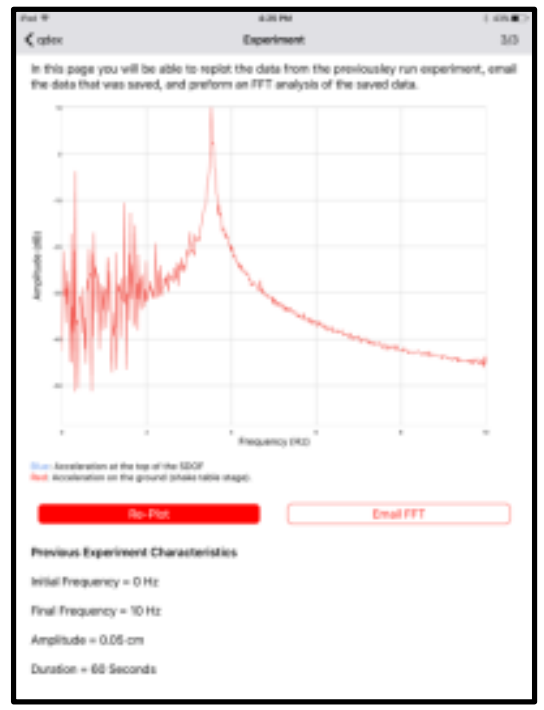

(c)

Figure 8. Experiment Component - Data Post-processing 
The objectives of the Experimental component are as following, which are targeted to fulfil course objectives 2 and 4 :

- To perform physical shake table experiments and identify basic operation principles of the sensors and shake table

- To observe the behavior of a SDOF structure under excitations with different dominant frequencies experimentally

- To understand the concept of natural frequency and its effects on the response of the structure experimentally

- To analyze and determine a SDOF system equation of motion and transfer function experimentally

\section{Surveys and Results}

After being introduced to the necessary concepts in the classroom, the students were given access to the mobile learning module as a course project. Pre-survey and post-survey were developed in Qualtrics ${ }^{15}$ and given to students right before and after using the mobile laboratory module to document student characteristics, their perception and readiness to mobile learning, and the effectiveness of the proposed module to increase their knowledge competence and achieve the course learning outcomes. The contents in the pre- and post-surveys are shown in Table 1.

Table 1. Survey Content

\begin{tabular}{|l|l|}
\hline Pre-survey: & Post-survey: \\
\hline Students characteristics & Experience with the mobile learning module \\
\hline $\begin{array}{l}\text { Previous experience on mobile learning } \\
\text { Openness to mobile learning }\end{array}$ & Openness to mobile learning \\
\hline Knowledge competence & Knowledge competence \\
\hline Unidentifiable identifiers & Unidentifiable identifiers \\
\hline & Comments/suggestions on improvement \\
\hline
\end{tabular}

In order for the surveys to remain anonymous while being able to compare the pre- and postsurveys, "unidentifiable identifiers" are created. The students were asked to provide the first 4 letters of the town they were born in and the last 4 numbers of their phone numbers. By matching these two parameters in the pre- and post-surveys, the results can be compared without knowing who they are.

The participation in the survey was voluntary and did not contribute to students' grade. With a total of 34 students in the class, 33 of them participated in the pre-survey and 21 participated in the post-survey. Among these participants $(n=33), 76 \%$ are male and $24 \%$ are female. $38 \%$ of them are Asian, $21 \%$ White, $21 \%$ classified themselves as others, $7 \%$ with two or more races, $7 \%$ prefer not to answer, and $3 \%$ as native Hawaiian or other pacific islanders. In terms of participants' current status, $62 \%$ are senior undergraduate students, $24 \%$ are graduate students, and $13 \%$ are students in other levels. According to the responses $(n=33), 97 \%$ of the participants own a smartphone or a tablet while all of those who currently didn't responded that they plan to get one in the near future. To evaluate what is the main usage of their mobile devices, they were 
asked how many times they use the mobile devices daily for entertainment, obtain information (e.g. estimate bus arrival time, get direction, find places for dinner and etc.), and learning activities (e.g. read article, take online course, listen to lecture recording and etc.). The responses $(n=33)$ are shown in Figure 9.

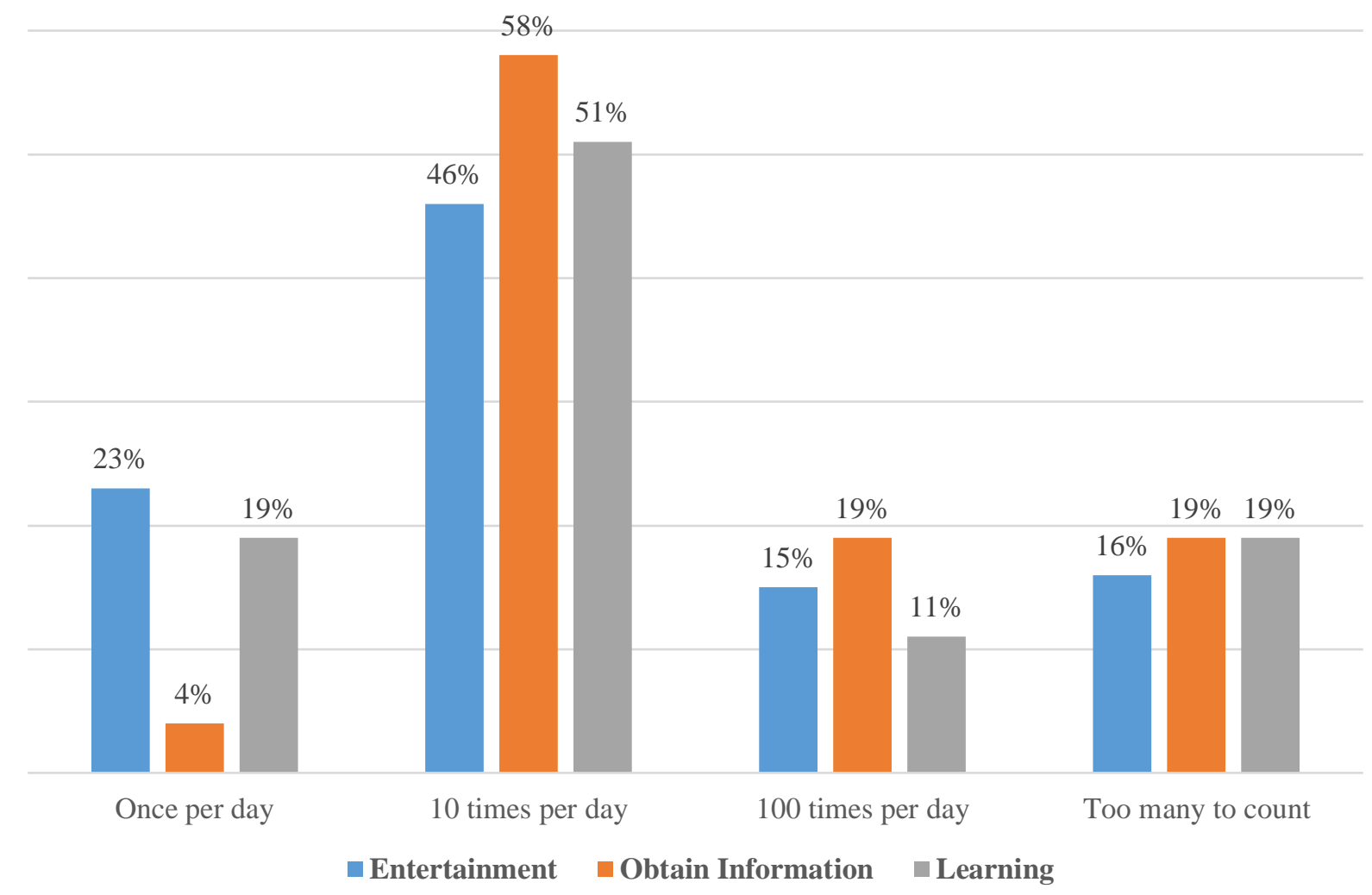

Figure 9. Activities of Using Mobile Devices

Majority of the respondents use their mobile devices for entertainment, obtain information and learning at a reasonable frequency (10 times per day) while about $40 \%$ of the respondents expressed addiction to the devices (100 times per day and too many to count). For respondents who use mobile devices more than once per day, obtaining information seems to be the most popular usage of the mobile devices, closely followed by learning and entertainment. This demonstrated the acceptance of mobile learning among the current generation.

The openness to the mobile learning was evaluated in both pre- and post-survey to see whether the students' perception was changed after using the learning module. When being asked how they feel about using smartphone/tablet as a learning tool, $92 \%$ of the respondents $(n=21)$ supported the statement in the pre-survey and similar responses are observed in the post-survey $(90 \%)$.

Six questions, as shown in Table 2, were asked in both pre- and post-surveys to evaluate whether the module improves students' understanding and increases their knowledge competence on the critical concepts for this course. The students were given the options to choose whether they understand the statement, understand but don't know the answer, statement is true and statement 
is false. The percentage of respondents $(n=21)$ who chose the correct answers in the pre-survey is compared to that in the post-survey. As can be seen in Table 2, in most of the questions except one, the correctness increases anywhere from $8 \%-29 \%$ (positive denotes increase), which demonstrates the usefulness of the learning module on students' knowledge competence improvement.

Table 2. Questions on Knowledge Competence

\begin{tabular}{|l|c|c|c|}
\hline \multirow{2}{*}{ Question } & \multicolumn{2}{|c|}{ Correctness } \\
\cline { 2 - 4 } & Pre & Post & Diff. \\
\hline $\begin{array}{l}\text { 1. In order to find the equation of motion of a structure, the } \\
\text { calculations of mass, stiffness and damping coefficient are necessary. }\end{array}$ & $60 \%$ & $89 \%$ & $+29 \%$ \\
\hline $\begin{array}{l}\text { 2. Given the free vibration response of a single degree of freedom } \\
\text { (SDOF) structure, its damping ratio can be calculated by using the } \\
\text { half-power bandwidth method. }\end{array}$ & $24 \%$ & $47 \%$ & $+23 \%$ \\
\hline $\begin{array}{l}\text { 3. When the SDOF structure is being excited by its natural frequency, } \\
\text { the amplitude of the structural response will typically be several } \\
\text { times smaller than the excitation amplitude. }\end{array}$ & $48 \%$ & $67 \%$ & $+19 \%$ \\
\hline $\begin{array}{l}\text { 4. The inherent damping of a structure does not have effects on the } \\
\text { structural response under external excitations. }\end{array}$ & $64 \%$ & $72 \%$ & $+8 \%$ \\
\hline $\begin{array}{l}\text { 5. When the excitation frequency is higher than the natural frequency } \\
\text { of the SDOF structure, the response of the structure will be out of } \\
\text { phase of the excitation. }\end{array}$ & $80 \%$ & $78 \%$ & $-2 \%$ \\
\hline $\begin{array}{l}\text { 6. The acceleration response of a SDOF structure can be measured by } \\
\text { using a strain gauge mounted on the top of the structure. }\end{array}$ & $52 \%$ & $72 \%$ & $+20 \%$ \\
\hline
\end{tabular}

Looking deeper into this, in answering Question 2, 26\% of the respondents didn't understand the statement and $26 \%$ said that they understood the statement but didn't know the answer, while only $47 \%$ got the correct answer. This is showing that how to obtain the damping ratio of the SDOF structure is a place deserves more attention in this course. From Table 2, it is surprising to see the low correctness rate on Question 3 in both the pre- and post-survey as excitation at structure's natural frequency yielding larger amplitudes of oscillation than that of the input signal should be a key concept delivered in this course. This will be further investigated to evaluate if the topic is not covered sufficiently in the course. Besides, only $8 \%$ increase in correctness is observed on Question 4. The bonus slider as shown in Figure 5c would be a good tool to help students understand the effects of damping on structural responses. It will be considered to allow access to this function from the beginning (not use as bonus) for future implementation. It is also interesting to note that the correctness in Question 5 remains the same in the pre- and postsurvey. A contributing factor to this would be the fact that the phase concept is not emphasized in the learning module.

The user experience on the developed apps has also been investigated through a series of postsurvey questions. As indicated in Table $3(n=21)$, the feedback is very positive. $95 \%$ of the respondents found the apps easy to use and felt that using the apps were an enjoyable learning experience. $89 \%$ of them agreed that the app helped to improve their understanding on the critical concepts and $84 \%$ would recommend the learning module to a friend. The lowest score (74\%) on all the questions belongs to the performance of the apps. One of the contributing 
factors may be the fact that, although the apps are compatible with both iOS and Android, some students were using smartphones/tablets with relatively old version of the operation systems, which caused weird performance during the usage. This will be further looked into for future refinement of the learning module. $79 \%$ of the respondents strongly agreed/agreed that the apps can be navigated easily, indicating that there is room for improvement regarding the user interface.

Table 3. User Experience on Mobile Module

\begin{tabular}{|l|c|}
\hline Question & $\begin{array}{c}\text { Strongly } \\
\text { Agree/Agree }\end{array}$ \\
\hline 1. I found the apps easy to use. & $95 \%$ \\
\hline 2. I can navigate through the apps easily. & $79 \%$ \\
\hline 3. Using the apps were an enjoyable and satisfying learning experience. & $95 \%$ \\
\hline 4. The apps performed well and I completed my experiments successfully. & $74 \%$ \\
\hline 5. The instructions provided are clear enough. & $84 \%$ \\
\hline $\begin{array}{l}\text { 6. The assistance was provided in a timely manner when needed. } \\
\text { 7. The app helped to improve my understanding on concepts such as natural } \\
\text { frequency, equation of motion and structural responses under excitations with } \\
\text { different frequencies. }\end{array}$ & $89 \%$ \\
\hline 8. I would recommend the learning module to a friend. & $84 \%$ \\
\hline
\end{tabular}

In the post-survey, students are encouraged to provide additional comments/suggestions on the learning module. The responses are very encouraging. For example, a student wrote, "I actually really enjoyed the learning experience associated with the app. I found myself using it more than I expected; before bed even." and another comment says, "this telepresence will make future SFSU engineering courses using distance learning possible in manipulate experiments from office or home".

\section{Conclusions and Future Work}

A novel mobile remote laboratory was developed at SFSU to provide students the opportunity to experience the exciting physical shake table experiments right at their fingertips. To create a completely standalone mobile learning experience, a learning module consisted of interconnected components that deliver theory, provide practical examples, and allow for physical experimentations, has been further developed. The module was implemented, for the first time, in a senior level undergraduate course at SFSU in Fall 2016 to evaluate its effectiveness. Pre- and post-surveys were conducted right before and after using the module. Survey results demonstrated the readiness of the students towards mobile learning and showed promising results in increasing participants' knowledge competence. It is noted that the results are obtained from a relatively small sample size. More data/samples will be necessary to further evaluate the usefulness and effectiveness of the module and mobile laboratory. Besides, the results shown in this study are obtained using indirect measurements with student self-report data. In Fall 2017, the learning module is planned to be implemented again with the appropriate modifications. Student performance with direct measures will be compared to semesters without implementing the mobile learning module to further investigate the effectiveness of the module. 
With its superior accessibility, the mobile learning module/laboratory could be easily incorporated into fully online and flipped classes. The authors intend to seek opportunity to evaluate its potential in such applications.

\section{Acknowledgement}

The authors would like to thank the supports from the California State University Course Redesign with Technology program and the College of Science and Engineering and the School of Engineering in SFSU in developing the remote shake table laboratory. The authors would also like to acknowledge their partners in Quanser for the technical supports in the development process.

\section{References}

1. Gioia, D. A., and Brass, D. J., "Teaching the TV generation: The case for observational learning". Organizational Behavior Teaching Review, 10(2), 11-18, 1985.

2. Proserpio, L., and Gioia, D. A., "Teaching the Virtual Generation" Academy of Management Learning \& Education, 6(1), 69-80, 2007.

3. Jacob, Seibu Mary, and Biju Issac. "Mobile learning culture and effects in higher education." arXiv preprint arXiv:1410.4379 (2014).

4. Keegan D., "The Future of Learning: From elearning to mlearning". FernUniversität Hagen, Hagen, Germany, 2002.

5. Gao, Yong, Guangqiang Yang, B. F. Spencer, and George C. Lee. "Java-powered virtual laboratories for earthquake engineering education." Computer Applications in Engineering Education 13, no. 3 (2005): 200.

6. Sim, Sung-Han, B. F. Spencer, and G. C. Lee. "Virtual laboratory for experimental structural dynamics." Computer Applications in Engineering Education 17, no. 1 (2009): 80-88.

7. Katsanos, E. I., O. N. Taskari, and A. G. Sextos. "A matlab-based educational tool for the seismic design of flexibly supported RC buildings." Computer Applications in Engineering Education 22, no. 3 (2014): $442-451$.

8. Dyke, Shirley, Z. Jiang, R. Christenson, X. Gao, and S. Courter. "Teleoperation and teleparticipation of instructional shake tables using the NEES cyberinfrastructure." In Proc. of the World Forum on Smart Materials and Smart Structures Technology, Chongqing and Nanjing, May. 2007.

9. Dyke, Shirley, R. Christenson, Z. Jiang, X. Gao, and Z. Feinstein. "Tele-operation Tools for Bench-scale Shake Tables for Instruction in Earthquake Engineering." Seismological Research Letters 78, no. 4 (2007): $460-463$.

10. Balamuralithara, B., and P. C. Woods. "Virtual laboratories in engineering education: The simulation lab and remote lab." Computer Applications in Engineering Education 17, no. 1 (2009): 108-118.

11. Jiang, Zhaoshuo, and A. Maxwell. "Interactive Remote Shake Table Laboratory for Instruction in Earthquake Engineering." Proceeding of 2016 American Society for Engineering Education (ASEE) Annual Conference \& Exposition, New Orleans, LA, June 2016.

12. Nersessian, Nancy J. "Conceptual change in science and in science education." Synthese 80, no. 1 (1989): 163183.

13. Quanser. "qdex." Quanser.com. http://qdexapps.com (accessed April 8, 2017).

14. Double Robotics. "Telepresence Robot for Telecommuters." doublerobotics.com. http://www.doublerobotics.com (accessed April 8, 2017).

15. Qualtrics. "The Leading Research \& Experience Software." qualtrics.com. https://www.qualtrics.com (accessed April 8, 2017). 